\title{
Design of a targeting and Oxygen-independent platform to improve Photodynamic Therapy: A proof of concept
}

\author{
Ludivine Larue $, \dagger, \ddagger$ Tataye MOUSSOUNDA MOUSSOUNDA KOUMBA, $\diamond$ Nolwenn Le Breton, ${ }^{\circ}, \|$ Ber- \\ trand Vileno, ${ }^{\circ}, \|$ Philippe Arnoux, $†$ Valérie Jouan-Hureaux, $\perp$ Cédric Boura, $\perp$ Gérard Audran, $\diamond, *$ \\ Raphael Bikanga,§ Sylvain R. A. Marque, $\diamond$ Samir Acherar, $\neq$ and Céline Frochot, $†, *$
}

† Université de Lorraine, CNRS, LRGP, F-54000 Nancy, France ; ludivine.larue@univ-lorraine.fr, philippe.arnoux@univ-lorraine.fr, celine.frochot@univ-lorraine.fr ‡ Université de Lorraine, CNRS, LCPM, F-54000 Nancy, France ; samir.acherar@univ-lorraine.fr

$\diamond$ Aix Marseille Univ, CNRS, ICR, UMR 7273, case 551, Avenue Escadrille Normandie-Niemen, 13397 Marseille Cedex 20, France; g.audran@univ-amu.fr, sylvain.marque@univ-amu.fr, tataye.mousskoumb@gmail.com

${ }^{\circ}$ Institut de Chimie, UMR 7177, CNRS, Université de Strasbourg, 4 rue Blaise Pascal, F-67000 Strasbourg, France; nlebreton@unistra.fr, vileno@unistra.fr

\| French EPR Federation of Research, REseau NAtional de Rpe interDisciplinaire, RENARD, Fédération IR-RPE CNRS 3443, France

$\perp$ Université de Lorraine, CNRS, CRAN, F-54000 Nancy, France ; valerie.jouan-hureaux@univ-lorraine.fr, cedric.boura@univ-lorraine.fr

$\S$ Laboratoire de Substances Naturelles et de Synthèse Organométalliques, Université des Sciences et Techniques de Masuku, B.P. 943, Franceville, Gabon ; brbikanga@hotmail.fr

* Correspondence: celine.frochot@univ-lorraine.fr; Tel.: +33-3-72-74-37-80; g.audran@univ-amu.fr; Tel.: +33-4-91-28-88-62

KEYWORDS: photodynamic therapy, hypoxia, targeting, neuropilin-1, peptide, alkoxyamine, hemolysis, spin trapping

ABSTRACT:

Photodynamic therapy (PDT) is a promising technique to treat different kinds of disease especially cancer. PDT requires three elements: molecular oxygen, a photo-activatable molecule called the photosensitizer (PS) and appropriate light. Under illumination, the PSs generate, in the presence of oxygen, the formation of reactive oxygen species including singlet oxygen, toxic, which then destroys the surrounding tissues. Even if PDT is used with success to treat actinic keratosis or prostate cancer for example, PDT suffers from two major drawbacks: the lack of selectivity of most of the PSs currently used clinically as well as the need for oxygen to be effective. To remedy the lack of selectivity, targeting the tumor neovessels is a promising approach to destroy the vascularization and cause asphyxia of the tumor. KDPPR peptide affinity for the NRP-1 receptor overexpressed on endothelial cells has already been proven. To compensate for the lack of oxygen, we focused on photoactivatable alkoxyamines, molecules capable of generating toxic radicals by light activation. In this paper we describe the synthesis of a multifunctional platform combining three units: a PS for an oxygen-dependent PDT, a peptide to target tumor neovessels and an alkoxyamine for an oxygen-independent activity. The synthesis of the compound was successfully carried out, the study of the photophysical properties showed that the PS retained its capacity to form singlet oxygen, the affinity tests confirmed the affinity of the compound for NRP-1. Thanks to the Electron Paramagnetic Resonance (EPR) spectroscopy, a technique of choice for radical investigation, the radicals generated by the illumination of the alkoxyamine could be detected. The proof of concept was thus successfully established.

\section{INTRODUCTION}

Photodynamic therapy (PDT) is applied to treat many diseases ${ }^{1}$ such as age-related macular degeneration (AMD), actinic keratoses, Barrett's esophagus, prostate cancer.

PDT is a simple and efficient approach requiring three components to be effective: the light, the molecular oxygen (triplet oxygen ${ }^{3} \mathrm{O}_{2}$ ) and a photosensitizer (PS). All these components are non-toxic taken apart but taken together, they are able to destroy cells at a specific location. This modality of treatment requires the illumination of the PS by light. Thus, the PS moves from the ground state to singlet excited state ( $\left.{ }^{1} \mathrm{PS}^{*}\right)$. After intersystem-crossing a triplet excited state $\left({ }^{3} \mathrm{PS}^{*}\right)$ is formed. ${ }^{3} \mathrm{PS}^{*}$ reacts with surrounding molecular ${ }^{3} \mathrm{O}_{2}$ to generate radical oxygen species (ROS) by two main types of reactions: (i) type I which conducts at the generation of superoxide anion $\left(\mathrm{O}_{2}^{-\bullet}\right)$ and 
hydroxyl radical (HO•) (ii) type II where ${ }^{3} \mathrm{PS}^{*}$ transfers its energy to ${ }^{3} \mathrm{O}_{2}$ to produce reactive singlet oxygen $\left({ }^{1} \mathrm{O}_{2}\right) \cdot{ }^{1}$

Although PDT presents many well-known advantages, we can report, as well as for radiotherapy, the requirement of ${ }^{3} \mathrm{O}_{2}$ to be efficient. ${ }^{2}$ Indeed, the PDT leads to the consumption of ${ }^{3} \mathrm{O}_{2}$ inside the tumor and thus PDT-induced hypoxia as well as tumor pre-existing hypoxia limit its efficiency. To fight tumor hypoxia, six strategies from literature have been reported by us in a recent review ${ }^{3}$ : (1) the use of ${ }^{3} \mathrm{O}_{2}$ cargo to directly supply additional ${ }^{3} \mathrm{O}_{2}$ inside the tumor (oxyhemoglobin, perfluorocarbon...), (2) the modification of tumor microenvironment $\mathrm{CH}_{2} \mathrm{O}_{2}$ decomposition, decrease of tumor ${ }^{3} \mathrm{O}_{2}$ consumption...), (3) the use of combined therapies to have an additional effect to PDT (chemo-PDT, PTT-PDT...), (4) the fractional PDT to regulate tumor ${ }^{3} \mathrm{O}_{2}$ consumption, (5) the hypoxia-dependent PDT by using hypoxia-activated compounds (azobenzene) and (6) hypoxia-independent PDT by using compounds which do not need ${ }^{3} \mathrm{O}_{2}$ to be cytotoxic (PDT type I, NO or ${ }^{1} \mathrm{O}_{2}$ donor and photoactivatable compounds). The use of photoactivatable compounds that do not require ${ }^{3} \mathrm{O}_{2}$ to be effective appeared to be particularly interesting.

Alkoxyamines (Alks), with $\mathrm{R}_{1} \mathrm{R}_{2} \mathrm{NO}-\mathrm{R}_{3}\left(\mathrm{R}_{1}, \mathrm{R}_{2}\right.$ and $\mathrm{R}_{3}$ as alkyl chains) as general structure, are interesting molecules for therapeutic aspects. Indeed, as depicted in the Scheme 1 , alks having weak energy bond of NO- $\mathrm{R}_{3}$ could release two radical species: a stable nitroxide $\left(\mathrm{R}_{1} \mathrm{R}_{2} \mathrm{NO}^{\circ}\right)$ and a transient alkyl radical $\left(\mathrm{R}_{3}{ }^{\circ}\right)$. Moreover, both radicals could be coupled together to reform an alk. ${ }^{4}$ Thus, this radical reactivity of alks has been intensely investigated in NMP (Nitroxide Mediated Polymerization). ${ }^{5}$ Several relationships were developed linking the rate constants of homolysis $\mathrm{k}_{\mathrm{d}}$ to polarity, bulkiness, and stability parameters of both the nitroxide $\left(\mathrm{R}_{1} \mathrm{R}_{2} \mathrm{NO}^{\circ}\right)$ and alkyl fragments $\left(\mathrm{R}_{3}{ }^{\circ}\right) .^{6}$ In 2014 , we reported a proof of concept for a new application of alks as theranostic agents against cell tumours. $^{7}$ Thus, the release radical as therapeutic agent triggered the apoptosis of cancer cells in vitro and the nitroxide as diagnostic probe in imaging by Overhauser MRI. Recently, we optimized the efficiency of these reactive species to destroy malignant cells in vitro ${ }^{8}$ and reported in vivo experiments in mouse. ${ }^{9}$

$$
\begin{aligned}
& \underset{\mathrm{R}_{2}^{\prime}}{\mathrm{R}_{1}^{\mathrm{R}}-\mathrm{O}^{\prime}} \underset{\text { recombination }}{\stackrel{\mathrm{R}_{3}}{\text { homolysis }}} \underset{\mathrm{R}_{2}^{\prime}}{\stackrel{\mathrm{R}_{1}^{\prime}}{\mathrm{R}^{\prime}}} \mathrm{O}^{\cdot}+\mathrm{R}_{3} \cdot \\
& \text { Alkoxyamine Nitroxide Alkyl }
\end{aligned}
$$

\section{Scheme 1. Reversible NO- $\mathbf{R}_{3}$ bond in alks.}

Another limit of PDT is the low selectivity of the majority of the commercial PSs. The selectivity is therefore due to the possibility to confine the PS by restricting the light illumination to a specific region. However, this strategy is limited in some cases (spread metastases for example) needing a broader illumination. It is necessary to develop modified PSs able to target effectively the cancer cells by a specific accumulation into the tumor or the neovessels surrounding the tumor. ${ }^{10}$ The destruction of the vascular system allows the eradication of the tumor, following the $\mathrm{O}_{2}$ deprivation and nutrients essential to life. ${ }^{11}$ Therefore, the tumor vascular system is a promising target for creating damage by PDT. Specific receptors of endothelial cells, such as vascular endothelial growth factor receptors (VEGF) or neuropilin-1 co-receptor (NRP-1) can be used as molecular targets. ${ }^{12}$

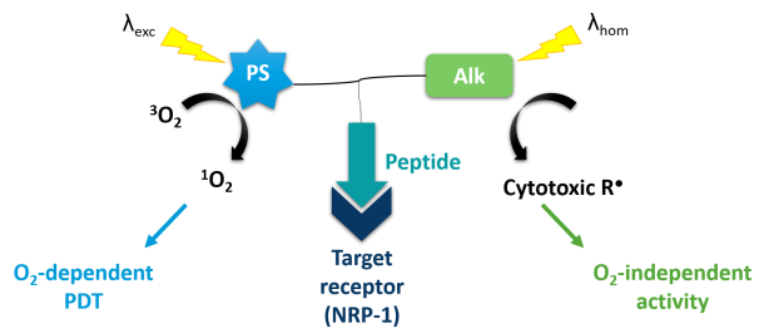

Figure 1. Schematic representation of trimodal platform.

Herein, we design trimodal platform for a targeted-PDT treatment efficient in both normoxic and hypoxic conditions. The designed platform, named Alk-K(Pyro-a)DKPPR, is based on three unities: (1) pyropheophorbide-a (Pyroa) as a PS, which could be illuminated in the red region $\left(Q_{I}\right.$ = $668 \mathrm{~nm}$ ) to have an $0_{2}$-dependent PDT, (2) KDKPPR, a NRP-1-targeted peptide has already been proven by our team and (3) a homolyzable alk, under UV illumination, to produce alkyl radicals in order to have an $\mathrm{O}_{2}$-independent PDT (Figure 1). For the evaluation of the relevance of these new platforms, the synthesis of the following compounds is necessary: the bimodal platform without Alk (i.e. K(Pyro-a)DKPPR) on the one hand and the bimodal platform without Pyro-a (i.e. Alk-KDKPPR) on the other hand. In this study, we aim to establish the proof of concept that the combination of these three unities is possible without any disruption of their proper properties.

RESULTS AND DISCUSSION

\section{Synthesis}

Alk (RS/SR)-6 was prepared in 4 steps in $37 \%$ overall yield. First, allylic bromination of 4-ethylbenzophenone 1 using $N$-bromosuccinimide (NBS) in $\mathrm{CCl}_{4}$ afforded the bromide derivative $(R / S)-2$ in $92 \%$ yield (Scheme 2). ${ }^{13}$ Then, the alkyl radical was generated in situ by the action of copper catalysts to the nitroxide $(R / S)-3^{14}$ with the bromide derivative yielded the alk 4 as a $4: 1$ mixture of diastereoisomers (55\%).

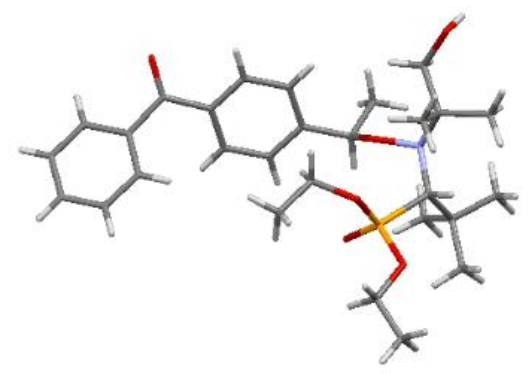

Figure 2. X-Ray structure of alk (RS/SR)-4. ${ }^{15}$

At this stage, the two diastereoisomers in racemic form were separated using column chromatography to afford $2.95 \mathrm{~g}$ of $(R S / S R)-4$ and $0.80 \mathrm{~g}$ of $(R R / S S)-4$. Thanks to recrystallization of $(R S / S R)-\mathbf{4}^{15}$ in diethyl ether white crystals suitable for X-ray analysis were obtained (Figure 2). 
Finally, alk $(R S / S R)-6$ was obtained through two successive oxidations with Dess-Martin periodinane (DMP) ${ }^{16}$ and
Pinnick oxidation procedure in $73 \%$ yield. ${ }^{17}$
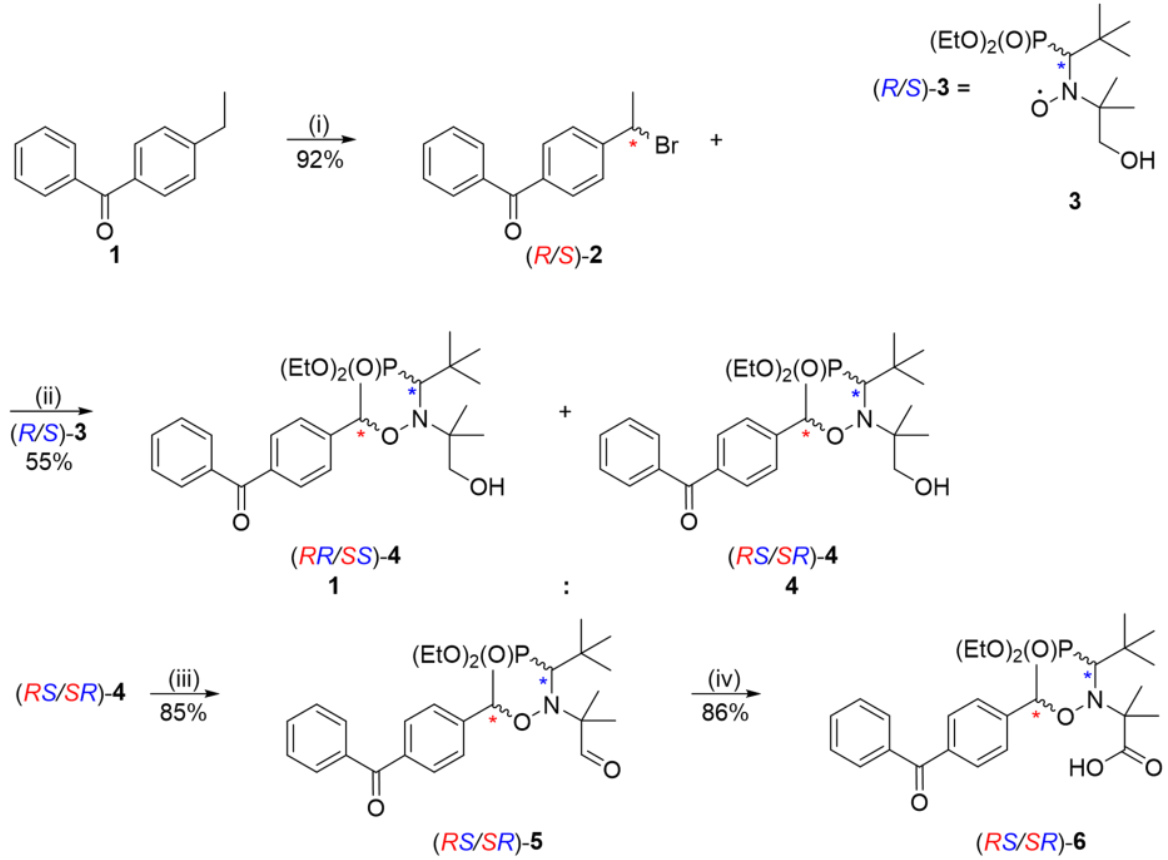

Scheme 2. Synthesis of alk (RS/SR)-6. (i) NBS, $\mathrm{CCl}_{4}$, reflux, $5 \mathrm{~h}$, (ii) $\mathrm{Cu} / \mathrm{CuBr}, \mathrm{rt}$, 12h, PMDTA, benzene, (iii) DMP, DCM, $0^{\circ} \mathrm{C}$, 5h, and (iv) $\mathrm{NaClO}_{2} / \mathrm{NaH}_{2} \mathrm{PO}_{4}, t$-BuOH, rt, 1.5h.

The amino acid lysine was chosen to link the three units (peptide, Alk and PS) together in our trimodal platform. First, the coupling reaction of the Pyro-a with the $(\varepsilon)$ amino group of lysine was done separately and performed in two steps in liquid phase to afford Fmoc-K(Pyro-a) as described previously by our team (Figure 3). ${ }^{18}$

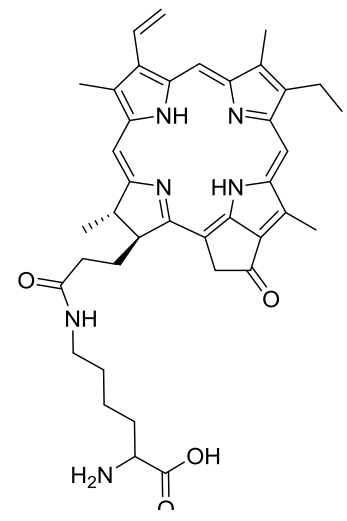

Figure 3. Structure of Fmoc-K(Pyro-a).

All the platforms, Alk-KDKPPR (9), K(Pyro-a)DKPPR (12) and Alk-K(Pyro-a)DKPPR (13) were prepared using a Fmoc/ $t \mathrm{Bu}$ solid phase peptide synthesis (SPPS) on 4benzyloxybenzyl alcohol (Wang) resin (Scheme 3) and characterized by HR-MS and ${ }^{1} \mathrm{H}$ NMR (See Supporting information). First, the peptide Fmoc-KDKPPR-wang resin $\mathbf{8}$ and Fmoc-DKPPR-wang resin $\mathbf{1 0}$ with protected lateral chains was synthesized. From these peptides, the bimodal platforms without Pyro-a (i.e. Alk-KDKPPR, 9) and without Alk (i.e. K(Pyro-a)DKPPR, 12), and the trimodal platform Alk-K(Pyro-a)DKPPR 13 were generated. The bimodal platform 9 was obtained after coupling reaction at the $\mathrm{N}$ terminal extremity of peptide 8 with $(R S / S R)-\mathbf{6}$, followed by both cleavages under acidic conditions (27\% overall yield from 7 with a HPLC purity of 95\%) of the peptide from the resin and of the lateral chains. The other bimodal platform 12 was isolated after a coupling reaction at the $\mathrm{N}$ terminal extremity of peptide $\mathbf{1 0}$ with Fmoc-K(Pyro a) to afford 11, then resin-cleaved and fully deprotected $(25 \%$ overall yield from 7 with a HPLC purity of 100\%). Finally, the trimodal platform 13 was obtained after similar procedure as 9 from 11 with (RS/SR)-6, (19\% overall yield from 7 with a HPLC purity of $98 \%$ ) (Figure 4).

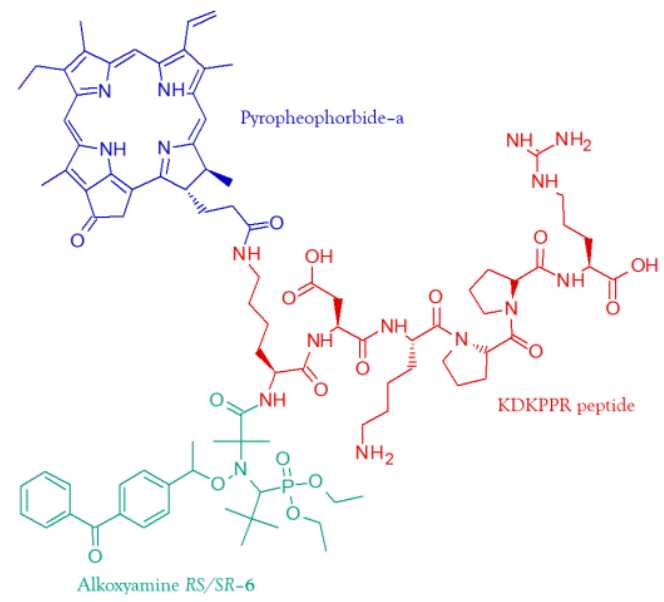

Figure 4. Structure of the trimodal platform 13. 


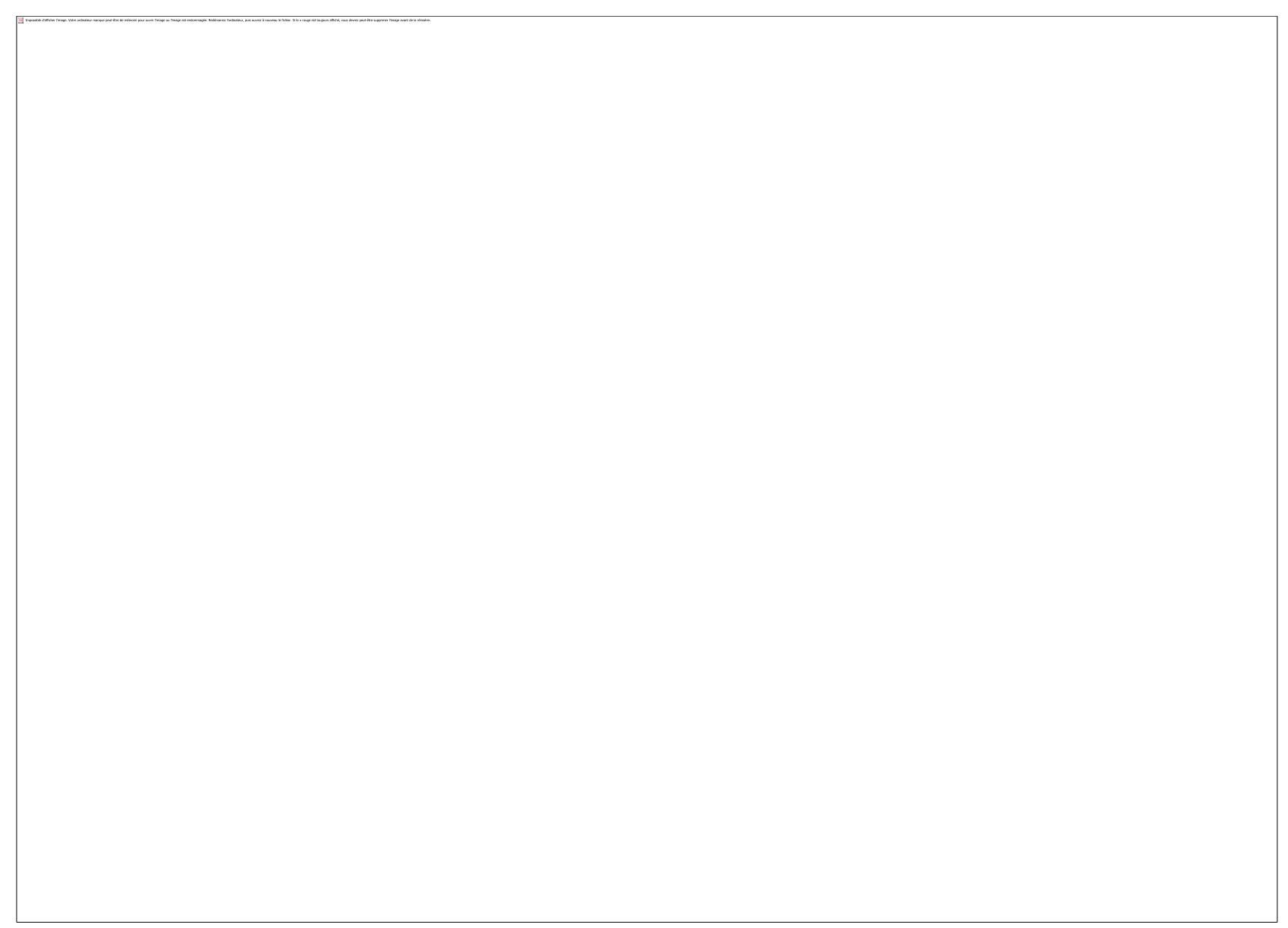

Scheme 3. Solid phase peptide synthesis of bimodal (9 and 12) and trimodal (13) platforms: (i) $N$-Deprotection: DMF/Pip (80:20, v:v), rt, 4 then 7 min (synthesizer) or 4x15 min (manually) (ii) Coupling: Fmoc-AA(P)-OH, HBTU, NMM, NMP, DMF, rt, 2 x 18 min, (iii) Coupling: PyBOP, DIPEA, DMF, rt, 12 h, (iv) Coupling: HBTU, NMM, NMP, DMF, rt, $12 \mathrm{~h}$ and (v) TFA/TIPS/water (92.5:2.5:5.0, v:v:v), rt, 1h30. Legend: $x$, number of amino acid.

\section{Photophysical properties}

The photophysical properties of the synthesized platforms (9, 12 and 13) as well as those of (RS/SR)-6 and Pyro-a alone were evaluated. These last two were used as references to test the influence of each moiety on the photophysical properties of Pyro-a. The photophysical studies were performed in methanol in which all the compounds were soluble. The absorption spectra of each compound were recorded at several concentrations to determine the $\varepsilon$ values (Figure 5A). A slight decreased of the $\varepsilon$ of Pyro-a was observed for the Soret and $\mathrm{Q}_{\mathrm{I}}$ bands after conjugation with the peptide and alk moieties, but it remained high for PDT applications.

The absorption spectrum showed the typical absorption bands of Pyro-a at 410 (Soret band), 508 (Q $609\left(\mathrm{Q}_{\mathrm{II}}\right)$ and $666\left(\mathrm{Q}_{\mathrm{I}}\right) \mathrm{nm}$. Moreover, the coupling of the peptide and alk led to the apparition of a band at 214 and $270 \mathrm{~nm}$, respectively (Figure 5B).
Solutions of Pyro-a, $(R S / S R)-6,9,12$ and 13 were prepared at a concentration allowing an absorbance of about 0.2 . The fluorescence spectra were performed at an excitation wavelength at $410 \mathrm{~nm}$ for compounds containing Pyro-a (Figure 5C) and at $280 \mathrm{~nm}$ for compounds containing ( $R S / S R$ )-6 (data not shown). The fluorescence quantum yields, $\Phi_{\mathrm{f}}$, could then be calculated (Figure $5 \mathrm{~A}$ ). No fluorescence was observed for compounds that do not contain Pyro-a (i.e. (RS/SR)-6 and 9). The ${ }^{1} \mathrm{O}_{2}$ emission spectra were carried out under the same conditions in order to determine the quantum yield of ${ }^{1} \mathrm{O}_{2}, \Phi_{\Delta}$ (Figure $5 \mathrm{~A}$ and Figure 5D).

As for the fluorescence, no ${ }^{1} \mathrm{O}_{2}$ production was highlighted for compounds (RS/SR)-6 and 9. It could be observed that there was a slight decrease of both quantum yields for 12 in comparison with Pyro-a. Moreover, for 13, no change was observed. These results indicated that alk and peptide were not found to affect the photophysical properties of Pyro-a. 


\begin{tabular}{|c|c|c|c|c|}
\hline & & Pyro-a & 12 & 13 \\
\hline \multirow{5}{*}{$\begin{array}{c}\varepsilon\left(10^{3}\right) \\
\underset{1}{\left(L_{1} . \mathrm{mol}^{-1} \cdot \mathrm{cm}\right.}\end{array}$} & $\begin{array}{l}\text { Soret } \\
\text { Band }\end{array}$ & 91.1 & 64.1 & 51.8 \\
\hline & $\mathrm{Q}_{\mathrm{IV}}$ & 9.8 & 6.5 & 5.3 \\
\hline & $\mathrm{Q}_{\mathrm{III}}$ & 8.9 & 6.0 & 5.1 \\
\hline & $\mathrm{Q}_{11}$ & 8.5 & 5.6 & 5.1 \\
\hline & $a_{1}$ & 42.8 & 27.9 & 23.7 \\
\hline \multicolumn{2}{|c|}{$\Phi_{f}(\%)$} & 34 & 28 & 32 \\
\hline \multicolumn{2}{|c|}{$\Phi_{\Delta}(\%)$} & 54 & 50 & 54 \\
\hline
\end{tabular}
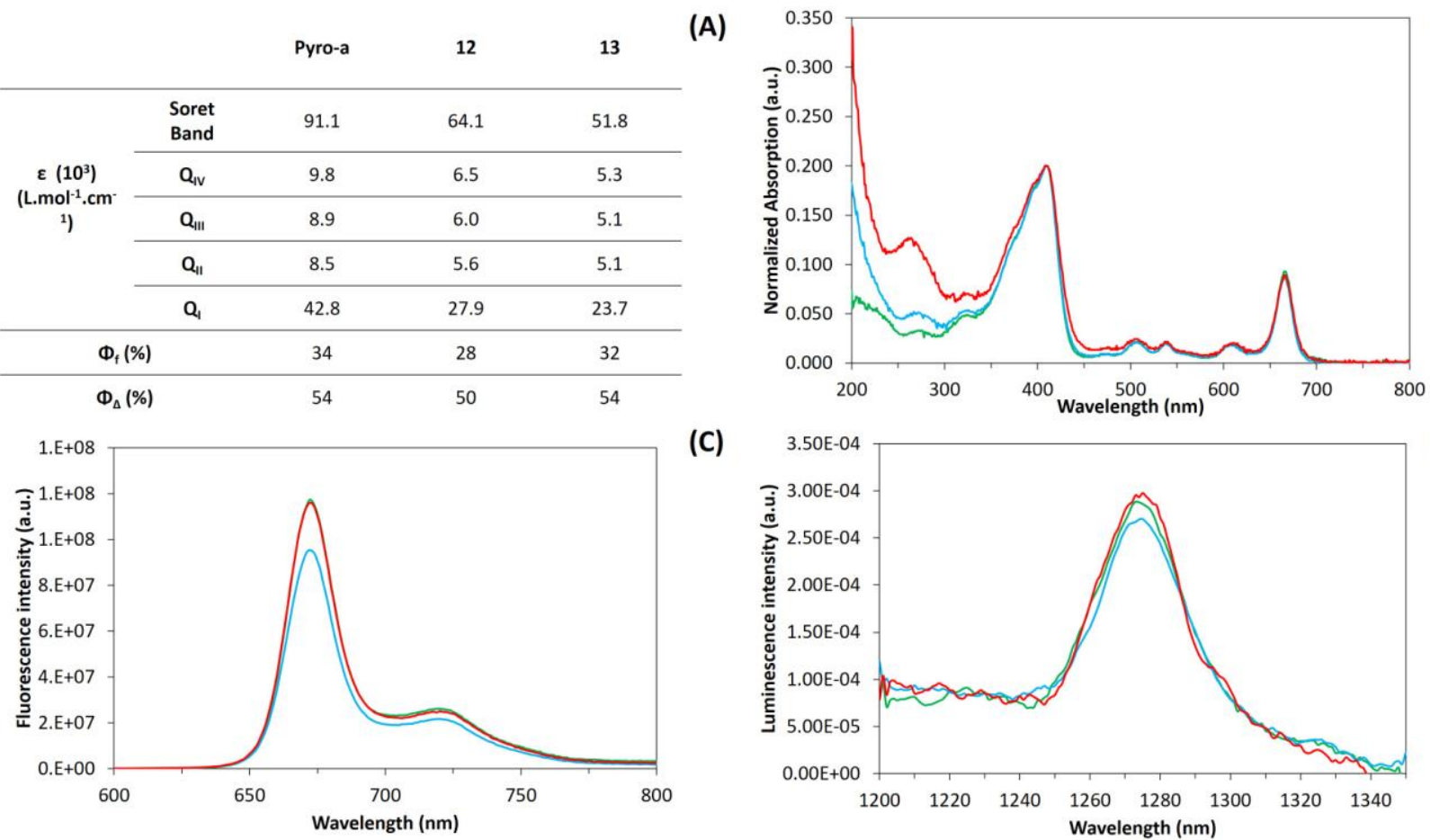

(C)

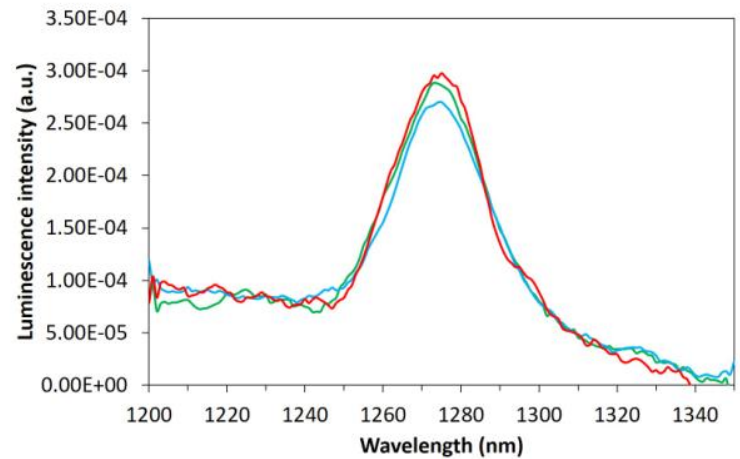

Figure 5. Photophysical properties of compounds with Pyro-a in methanol: (A) Absorption coefficient, $\Phi_{\mathrm{f}}$ and $\Phi_{\Delta}$ (B) Normalized UV-Visible Absorption spectra, (C) Fluorescence emission spectra $\left(\lambda_{\text {exc }}=410 \mathrm{~nm}\right)$ and (D) ${ }^{1} \mathrm{O}_{2}$ emission spectra $\left(\lambda_{\text {exc }}\right.$ $=410 \mathrm{~nm}$ ) of Pyro-a, 12 and 13. Legend: (-) Pyro-a, $(-) 12$ and (-) 13.

\section{Photobleaching studies}

The stability of Pyro-a, $\mathbf{1 2}$ and $\mathbf{1 3}$ under light illumination (668 $\mathrm{nm}, 10 \mathrm{~mW} \cdot \mathrm{cm}^{-2}$ ) in methanol was studied to check the non-photobleaching of the PS over time. The $\Phi_{\mathrm{f}}$ was evaluated every $5 \mathrm{~min}$ and a significant stability was observed for all the compounds (Figure 6). Moreover, we could observe that $\Phi_{\Delta}$ was the same at the beginning and at the end of the illumination.

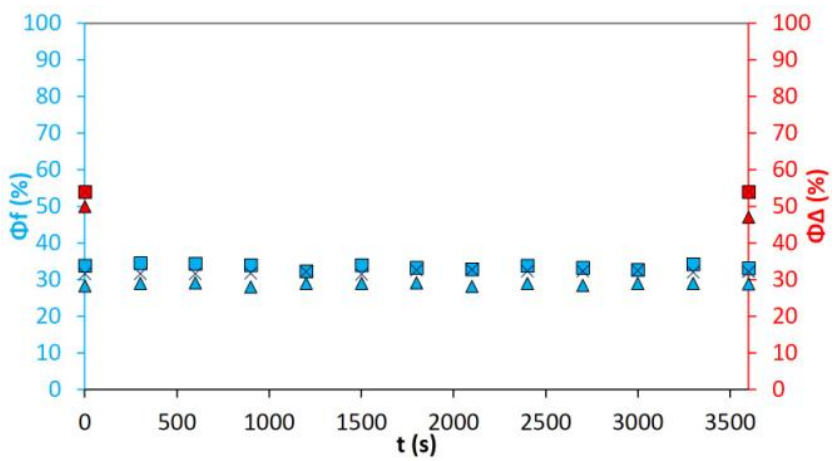

Figure 6. Evolution of $\Phi_{\mathrm{f}}$ and $\Phi_{\Delta}$ quantum yields of compounds Pyro-a, 12 and 13 under light irradiation $(668 \mathrm{~nm}$, $10 \mathrm{~mW} . \mathrm{cm}^{-2}$ ) over time. Legend: (口) Pyro-a, $(\Delta)$ 12, $(\times)$ 13.

\section{Photolability studies}

Scheme 4 showed the radicals production from the alk used in our model. To evaluate the effective homolysis of our compounds, we followed the generation of SG1 radical by Electron paramagnetic resonance (EPR) spectroscopy. A high stability of this radical was observed after more than 1 hour of irradiation with a decrease of intensity from $100 \%$ to $93 \%$ (data not shown).

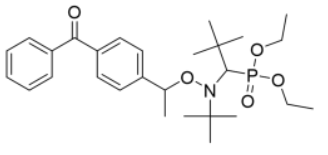

Alk
SG

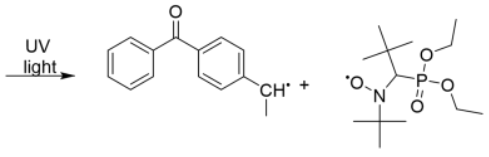

\section{Scheme 4. Alk homolysis under UV light irradiation.}

First, we opted to evaluate the influence of Alk concentration and oxygenation of the solution on the SG1 generation though spin-trapping investigations upon UVA-light illumination $(\lambda=365 \mathrm{~nm})$ of Alk. We used, as reference conditions, a $300 \mu \mathrm{M}$ solution of Alk in methanol under normal conditions of oxygenation and illumination (see Material and Methods section). While doing so, EPR fingerprint of the Alk was detected. It consisted of 6 lines of equal intensity arising from the coupling between the single unpaired electron and both ${ }^{31} \mathrm{P}$ and ${ }^{14} \mathrm{~N}$ nuclear spin of $1 / 2$ and 1 respectively (hyperfine coupling values are given in Supporting Information). ${ }^{19}$ From the very first seconds of illumination a fast production of SG1 was observed reaching a maximum EPR intensity after ca. $75 \mathrm{~s}$ of illumination. After this, a sharp decline of the intensity was observed (Figure 7A). The marked change in the evolution of the EPR intensity is also referred to as turnover between the radical generation (or spin adduct) and their reduction. The illumination of Alk at different concentration exhibited a linear dependence of the initial rate of SG1 production (Table 1) together with the Alk concentration. This trend was accompanied with a shift of the turnover towards higher illumination time (Figure 7A), yet such turn- 
over was observed whatever was the Alk concentration. Similar investigations were performed on the compounds 9 and 13 (Figure 7B and 7C, respectively). Doubling the compounds concentrations were not sufficient here to double the corresponding initial rates while the presence of a well-defined turnover was also detected. The major difference was the time of illumination necessary to reach the turnover. Indeed, if the kinetics were comparable for the Alk alone and the compound $\mathbf{9}$, the kinetic was significantly longer for the compound $\mathbf{1 3}$ which may be due to the presence of the PS. Considering the significant UV light absorption of PS, this latter may compete with the Alk, sharing the amount of photons received and increasing the time to reach the maximal quantity of nitroxide. However, some unexpected kinetic effect may account for these observations (vide infra).
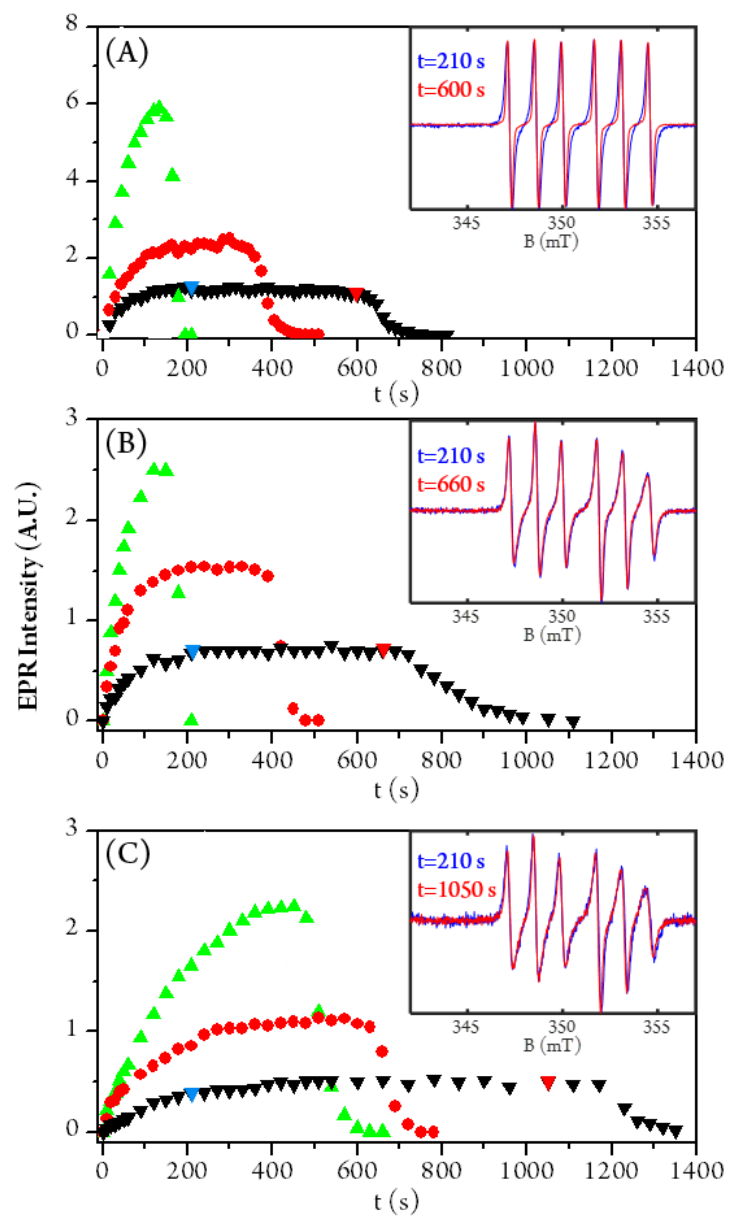

Figure 7. EPR intensity of radical generated after different irradiation time at room temperature for Alk (A), 9 (B) and $13(C)$ at different concentrations in methanol. Inset: EPR spectra, normalized by their peak to peak intensity, of SG1 of the solution at $75 \mu \mathrm{M}$ at the beginning of the plateau (blue) and at the end of the plateau (red). Legend: ( $\triangle$ ) 300 $\mu \mathrm{M},(\bullet) 150 \mu \mathrm{M}$ and ( $) 75 \mu \mathrm{M}$.

Worthy of note, EPR spectra of Alk sharpen upon irradiation (Figure 7A, inset), pointing to a decrease in $\mathrm{O}_{2}$ concentration within the organic solvent. ${ }^{20}$ Interestingly this ef- fect wasn't observed neither for 9 nor 13. The utmost importance of ${ }^{3} \mathrm{O}_{2}$ for the formation of radicals after irradiation of Alk was even strengthened by degassing the alk solution by mean of soft Argon bubbling (ca. $5 \mathrm{~mL} / \mathrm{min}$ ) prior to EPR investigations. In such hypoxic conditions, close to no SG1 was observed (Figure 8A). Identical approach was performed on both 9 and 13 compounds yet stackable kinetics were obtained regardless of the oxygenation conditions (Figure $8 \mathrm{~B}$ and $8 \mathrm{C}$ ). The absence of difference in Figure $8 \mathrm{~B}$ and $8 \mathrm{C}$ is due to the presence of peptide and PS which play the role of alkyl radical scavengers. Indeed, in Figure 8A, a large amount of nitroxide is observed because alkyl radicals are scavenged by ${ }^{3} \mathrm{O}_{2}$ and back reaction is suppressed (S1) whereas in absence of ${ }^{3} \mathrm{O}_{2}$ back reaction occurs impeding the growth of nitroxide.

Table 1. Initial production rate $(k)$ of radical and $U V$ exposition time until reaching the turnover (turnover) for compound Alk, 9 and 13 at different concentrations in methanol.

\begin{tabular}{lll}
\hline Compound & $\mathbf{k}(\mathbf{A} . \mathbf{U})$. & $\mathbf{t}_{\text {Turnover }}(\mathbf{s})$ \\
\hline Alk $(\mathbf{7 5} \boldsymbol{\mu M})$ & $0.017 \pm 0.001$ & 630 \\
\hline Alk $(\mathbf{1 5 0} \boldsymbol{\mu M})$ & $0.031 \pm 0.002$ & 345 \\
\hline Alk $(\mathbf{3 0 0} \boldsymbol{\mu M})$ & $0.088 \pm 0.005$ & 135 \\
\hline $\mathbf{9}(\mathbf{7 5} \mu \mathrm{M})$ & $0.009 \pm 0.001$ & 720 \\
\hline $\mathbf{9}(\mathbf{1 5 0} \boldsymbol{\mu M})$ & $0.025 \pm 0.002$ & 390 \\
\hline $\mathbf{9}(\mathbf{3 0 0} \boldsymbol{\mu M})$ & $0.039 \pm 0.002$ & 150 \\
\hline $\mathbf{1 3}(\mathbf{7 5} \boldsymbol{\mu M})$ & $0.0031 \pm 0.0005$ & 1170 \\
\hline $\mathbf{1 3}(\mathbf{1 5 0} \boldsymbol{M M})$ & $0.011 \pm 0.001$ & 630 \\
\hline $\mathbf{1 3}(\mathbf{3 0 0} \boldsymbol{\mu M})$ & $0.014 \pm 0.001$ & 450 \\
\hline
\end{tabular}

The SG1 reduction together with the potential consumption of ${ }^{3} \mathrm{O}_{2}$ is in favour of the photo-induced formation of radical intermediates. To validate such hypothesis a spintrapping investigation was performed, using 5(Diethoxyphosphoryl)-5-methyl-1-pyrroline-N-oxide (DEPMPO) to trap unstable reactive species too short-lived to be observed in our experimental conditions. ${ }^{21}$ Indeed, the reaction between DEPMPO and targeted radical led to the formation of a more stable spin-adduct which could hence be detected by EPR spectroscopy (Scheme 5).

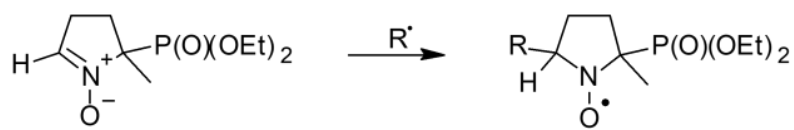

Scheme 5. Reaction between DEPMPO (EPR silent) and a short-lived radical leading to its corresponding spin adduct (EPR active).

As for SG1, DEPMPO spin-adducts exhibited the coupling between ${ }^{31} \mathrm{P}$ and ${ }^{14} \mathrm{~N}$ and the unpaired electron, yet with an additional ${ }^{1} \mathrm{H}$ having a nuclear spin of $1 / 2$. Consequently, EPR spectra of DEPMPO can have up to 12 lines. Noteworthy, the hyperfine coupling constants ( $h f c c s$ ) related to the hyperfine interaction within the adducts were characteristic of the nature of the trapped adduct, potentially allowing their identification (e.g. carbon- or oxygen-centred radical) (Figure $9 \mathrm{~A}) .^{22}$ 

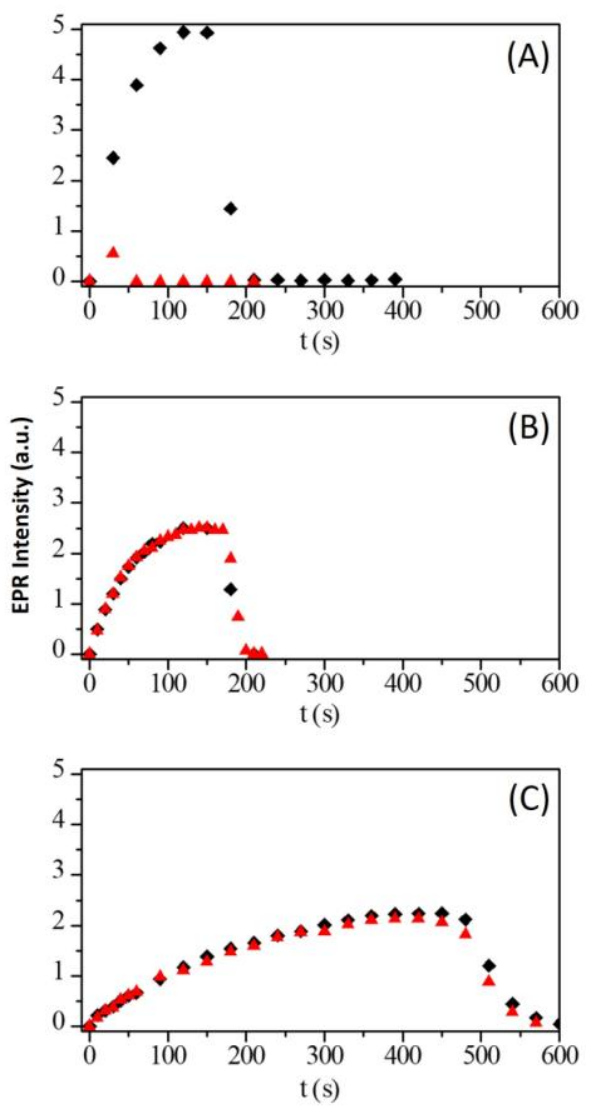

Figure 8. EPR intensity of radical generated after different irradiation time for Alk (A), 9 (B) and 13 (C) at $300 \mu \mathrm{M}$ in methanol with $(\bullet)$ or without $(\Delta)$ oxygen.
In presence of DEPMPO, a better stability of the radical SG1 generated over illumination time was observed in both oxygenated and degassed conditions: a break was still present at significantly longer illumination time and the corresponding signal decay was significantly slowed down (Figure 9B and 9C). Quite possibly, the spin-trap shielded the SG1 nitroxide site from potential reduction due to radical intermediates. Indeed, three distinct radical species were detected and identified. Based on the obtained hyperfine interactions, the first two radicals (herein referred as to $\operatorname{rad} 1$ and $\operatorname{rad} 2$ ) were identified as oxygenated radicals while the latter one (denoted as rad3) pointed towards carbon centred radical (See Supporting Information).

For the compound 9 (Figure 9B and 9C), a plateau was reached pointing to the high stability of the photogenerated nitroxide radical (SG1-peptide). For a methanol solution of 9 at $300 \mu \mathrm{M}$, a plateau around 500 seconds was which remained stable after 1 hour of illumination and that in both conditions of oxygenation. In these conditions, three distinct spin-adducts were also observed (see Supporting Information). This high stability of the nitroxide radical generated could be explained by a protecting effect due to the peptide.

Interestingly enough, for the compound 13 (Figure 9B and 9C), the same trend as for Alk alone was observed with a slower decay of the nitroxide signal in normal conditions of oxygenation. The generation of the same radicals as for 9 was also observed (see Supporting Information). This difference between the kinetics of compounds 9 and 13 might be explained by the fact that the introduction of the PS, a sterically large group, changed the structure of the peptide and changed the protective effect observed in its absence.

(A)
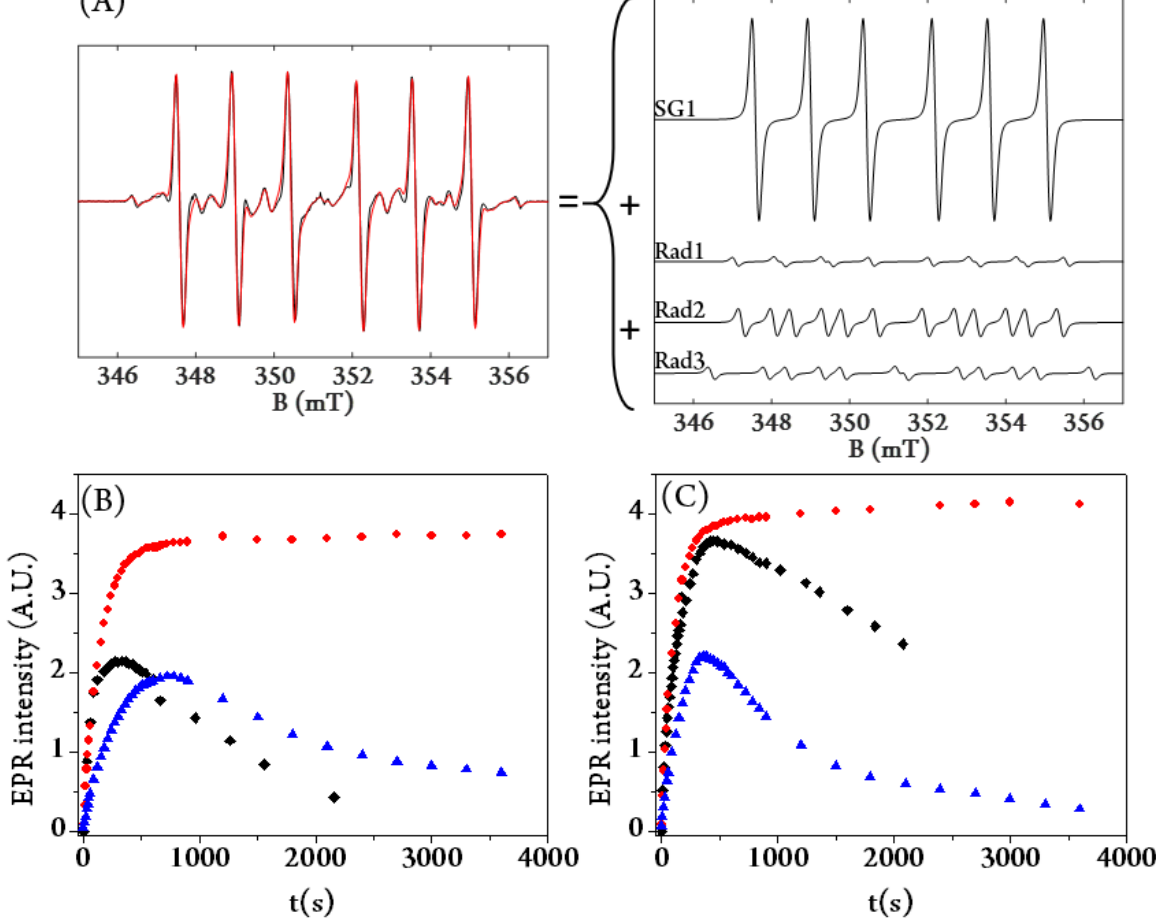

Figure 9. (A) Left: Simulation (red) and experimental (black) spectra of alk in presence of 10 mM of DEPMPO after 960 s of irradiation. Right: simulation of EPR spectra of SG1, Rad1, Rad2 and Rad3. Simulation parameters are given in Supplementary information. (B) and (C) Evolution of radical generation after illumination of Alk, 9 and $\mathbf{1 3}$ over time in solution in 
$\mathrm{MeOH}$ at $300 \mu \mathrm{M}$ in presence of $10 \mathrm{mM}$ of DEPMPO in (B) oxygenated solution and (C) degassed solution. Legend: Radicals formed by illumination of: ( )

The reduction of the nitroxide radical signal highlighted its strong reactivity with the surrounding environment and although there was competition between Alk and PS, the generation of nitroxide radicals was far from being blocked. This is very interesting for future biological applications for the destruction of cancer cells.

\section{Affinity studies}

The affinity of $\mathbf{9 , 1 2}$ and 13 to neuropilin-1 was evaluated by competitive ligand binding assay in comparison with the peptide KDKPPR alone. The binding of $\mathbf{1 2}$ and $\mathbf{1 3}$ to NRP-1 showed a better specificity than the peptide alone or 9 probably due to hydrophobic interactions enhanced by Pyro-a and steric interactions stabilizing the 3D conformation of the peptide (Figure 10). The affinity of $\mathbf{1 3}$ to NRP-1 (IC 50 of $0.46 \pm 1 \mu \mathrm{M}$ ) was relatively encouraging to envisage an evaluation of this new multimodal therapeutic approach on in vivo models of tumors expressing NRP-1.

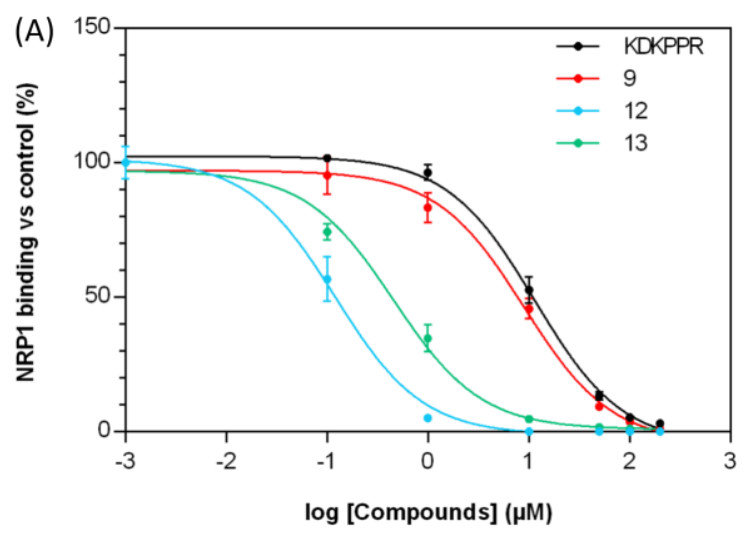

(B)

\begin{tabular}{lc}
\hline Compounds & IC50 $(\mu \mathrm{M})$ \\
\hline KDKPPR & $11.5 \pm 1$ \\
\hline $\mathbf{9}$ & $9.0 \pm 1$ \\
\hline $\mathbf{1 2}$ & $0.12 \pm 1$ \\
\hline $\mathbf{1 3}$ & $0.46 \pm 1$ \\
\hline
\end{tabular}

Figure 10. (A) Affinity of 9, 12 and $\mathbf{1 3}$ to NRP-1 evaluated by Binding Ligand Assay. (B) $\mathrm{IC}_{50}$ values of compounds estimated from affinity fitting curves.

\section{CONCLUSION}

Herein, we established the proof of concept that we can combine three entities, with their own properties, a PS, an alk and a peptide without any perturbations of their properties to overcome two major barriers of PDT. We report the effective synthesis of this innovative trimodal platform using SPPS with acceptable yield and high purities. The photophysical properties (quantum yields of fluorescence and ${ }^{1} \mathrm{O}_{2}$ ) of Pyro-a were maintained even coupled with peptide and the alk. The peptide KDKPPR still targeted NRP-1 after the coupling of Pyro-a and/or alk, even with a better affinity. The illumination of alk alone or coupled to the peptide or the PS led to the formation of radicals.

Concerning the photolability property of alks, compounds 9 and 13 presented two different kinetics. As an explanation, it might be suggested that the introduction of

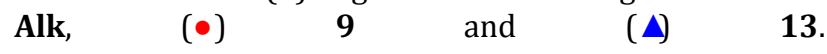

the bulky Pyro-a induced a change in the conformation of the peptide that lost its protective effect. This could be confirmed by the affinity studies where we can observe a better affinity for peptides coupling with Pyro-a than the peptide coupling only with $(R S / S R)-6$.

Although established, this proof of concept does not currently allow in vitro and in vivo applications due to the use of UV light for alk homolysis. We have to confirm our concept in vitro by developing others models of alk homolysable at higher wavelength.

\section{MATERIALS AND METHODS}

\section{Synthesis of compounds}

\section{Chemicals}

All commercially chemicals were used without further purifications. (3S-trans)-9-ethenyl-14-ethyl-4,8,13,18tetramethyl-20-oxo-3-phorbinepropanoic acid (pyropheophorbide a, Pyro-a) was purchased from BOC Sciences (Shirley, NY, USA). The Benzotriazole-1-yl-oxytris-pyrrolidino-phosphonium hexafluorophosphate (PyBOP) was purchased from Merck (Darmstadt, Germany). The Fmoc-Arg(Pbf)-Wang resin, 9-fluorenyl-methoxycarbonyl (Fmoc)-aminoacid-OH and $N, N, N^{\prime}, N^{\prime}$ Tetramethyl-0-(1H-benzotriazol-1-yl)uronium hexafluorophosphate) (HBTU) were purchased from Iris Biotech GmbH (Marktredwitz, Germany). The Fmoc-Lys$\mathrm{OH}$ hydrochloride, N-hydroxysuccinimide (NHS), $\mathrm{N}$-Ethyl$N$-(3-dimethylaminopropyl)carbodiimide hydrochloride (EDCI), acetic anhydride and trifluoroacetic acid (TFA) were purchased from Sigma-Aldrich (St Louis, MO, USA). The $N$-methylmorpholine (NMM), $N$-methylpyrrolidinone (NMP), N,N-Diisopropylethylamine (DIPEA) and triisopropylsilane (TIPS) were purchased from Alfa Aesar (Haverhill, MA, USA). Piperidine was purchased from Acros Organics. Ultrapure water (Milli-Q, $\rho>18 \mathrm{M} \Omega \cdot \mathrm{cm}$ ) was used for the aqueous solution preparation.

\section{Instruments}

Analytical thin layer chromatographies (TLC) were performed using Merck Kieselgel 60 F254 plates; spots were detected after UV light illumination and a phosphomolybdic acid solution in EtOH as a stain revealed by heating. Purifications of 2, (RR/SS)-4, (RS/SR)-4, $(R S / S R)-5$ and $(R S / S R)-6$ were done on a Reveleris ${ }^{\circledR} \mathrm{X} 2$ flash chromatography system (BUCHI, Switzerland) on Merck Kieselgel 60 (230-400 mesh). The synthesis of 2, $(R R / S S)-4,(R S / S R)-4,(R S / S R)-5$ and $(R S / S R)-6$ were realized under anhydrous conditions and an inert atmosphere of argon and, except where stated, using dried apparatus and employing standard techniques for handling airsensitive materials.

The peptides were synthesized with an automated ResPepXL peptide synthesizer (Intavis AG, Bioanalytical Instruments). The compounds were purified using Shimadzu LC-10ATvp, column Agilent Pursuit C18, $5 \mathrm{~mm}$ column $(5 \mu \mathrm{m}, 150 \times 21.2 \mathrm{~mm}$ ) equipped by an UV photodiode array detector (Varian Prostar 335-190-950 nm) and a spectrofluometric detector (Shimadzu RF-10AxL- 
200-650 nm). The UV detection was performed at 415 and $260 \mathrm{~nm}$. Fluorescence detection at $650 \mathrm{~nm}$ was realized after an excitation at $415 \mathrm{~nm}$. The analysis by HPLC were performed with the same equipment but with a column Agilent Pursuit 5 C18 $(5 \mu \mathrm{m}, 150 \times 4.6 \mathrm{~mm})$.

${ }^{1} \mathrm{H},{ }^{13} \mathrm{C}$, and ${ }^{31} \mathrm{P}$ NMR spectra of $2,(R R / S S)-4,(R S / S R)-4$, $(R S / S R)-\mathbf{5}$ and $(R S / S R)-\mathbf{6}$ were recorded in $\mathrm{CDCl}_{3}$ on a 300 or $400 \mathrm{MHz}$ spectrometer at Marseille and ${ }^{1} \mathrm{H}, \mathrm{COSY}$ and TOCSY NMR spectra of $\mathbf{9}, \mathbf{1 2}$ and $\mathbf{1 3}$ were recorded in DMSO-d 6 solvent at room temperature $(\mathrm{T}=298 \mathrm{~K})$ on a BRUKER AVANCE spectrometer at $300 \mathrm{MHz}$ at Nancy. Chemical shifts $(\delta)$ are given in parts per million (ppm) and using residual non- deuterated solvents as the internal reference for ${ }^{1} \mathrm{H}$ and ${ }^{13} \mathrm{C}-\mathrm{NMR}$ spectra, and as an internal capillary filled with $85 \% \mathrm{H}_{3} \mathrm{PO}_{4}$ for ${ }^{31} \mathrm{P}-\mathrm{NMR}$ spectra for 2 , $(R R / S S)-4,(R S / S R)-4,(R S / S R)-5$ and $(R S / S R)-6$ and using DMSO residual peak ( $\delta=2.5 \mathrm{ppm})$ as internal reference for 9, 12 and 13. Coupling constants (J) are given in hertz (Hz) and multiplicities are reported as follow: $\mathrm{s}=$ singlet, $\mathrm{d}=$ doublet, $\mathrm{t}=$ triplet, $\mathrm{q}=$ quadruplet, $\mathrm{m}=$ multiplet and $\mathrm{br}=$ broad.

High-resolution mass spectra (HR-MS) of 2, $(R R / S S)-4$, $(R S / S R)-4,(R S / S R)-5$ and $(R S / S R)-6$ were recorded on a SYNAPT G2 HDMS (Waters) spectrometer equipped with a pneumatically assisted atmospheric pressure ionization source (API). Positive mode electro- spray ionization was used on samples: electrospray voltage (ISV): $2800 \mathrm{~V}$; opening voltage (OR): $20 \mathrm{~V}$; nebulizer gas pressure (nitrogen): 800 L.h ${ }^{-1}$. Electron spray ionization mass spectra (ESI-MS) of compounds $\mathbf{9}, \mathbf{1 2}$ and $\mathbf{1 3}$ were recorded on a Brucker MicroTof-Q HR spectrometer in the "Service commun de Spectrométrie de Masse", Faculté des Sciences et Technologies (Vandoeuvre-lès-Nancy, France).

\section{Alcoxyamine synthesis}

Compound 2 has been synthetized by a reported procedure $^{23}$ (see SI) by using $10 \mathrm{~mol} \%$ of azobisisobutyronitrile instead of $1 \mathrm{~mol} \%$ of benzoyl peroxide.

The new compounds 4, 5, 6 have been prepared according to a reported procedure ${ }^{24}$ (see SI).

Solid phase peptide synthesis (SPPS)

The peptides K(Boc)D(OtBu)K(Boc)PPR(Pbf)-Wang resin 8 and $\mathrm{D}(\mathrm{OtBu}) \mathrm{K}(\mathrm{Boc}) \mathrm{PPR}(\mathrm{Pbf})$-Wang resin 10 were first synthesized using the automated ResPepXL peptide synthesizer, with a Fmoc/tBu methodology. The side chains of arginine, lysine and aspartic acid were respectively protected by $\mathrm{Pbf}, \mathrm{OtBu}$ and Boc groups. We used a Fmoc$\operatorname{Arg}(\mathrm{Pbf})$-Wang resin swelled in $\mathrm{CH}_{2} \mathrm{Cl}_{2}$. To remove the Fmoc group we used piperidine (20\% in DMF). This step was performed two times, a first during $4 \mathrm{~min}$ and a second during $7 \mathrm{~min}$. Then the next amino acid was grafted by adding an excess of Fmoc-aminoacid-OH ( 6 eq), HBTU (5 eq), NMP (3 eq) and NMM (10 eq) in DMF. This step was repeated two times for $18 \mathrm{~min}$. A last step of capping, using a solution of acetic anhydride ( $5 \%$ in DMF), was performed for $5 \mathrm{~min}$, to trap all functions that did not react. Deprotection, coupling and capping steps were repeated until the end of the synthesis of the peptide.

\section{Alk-KDKPPR, 9.}

After Fmoc deprotection, the reaction between (RS/SR)-6 (1.5 eq) and peptide $\mathrm{K}(\mathrm{Boc}) \mathrm{D}(\mathrm{OtBu}) \mathrm{K}(\mathrm{Boc}) \mathrm{PPR}(\mathrm{Pbf})-W a n g$ resin 8 was performed in presence of PyBOP (3 eq) and DIPEA (3 eq) in DMF, and the solution was stirred for $12 \mathrm{~h}$. The resin was dried under vacuum and then cleaved (with full deprotection of lateral chains) using TFA/TIPS/water $(92.5 / 2.5 / 5 \%)$ for $2 \mathrm{~h}$. The acidic resin was filtered and washed with $\mathrm{CH}_{2} \mathrm{Cl}_{2}$ and $\mathrm{EtOH}$. The filtrate was dried under vacuum and the compound was precipitated in ether by centrifugation. The final product was further purified by preparative HPLC using acetonitrile/water $0.1 \%$ TFA; $10 / 90$ ) to $100 \%$ acetonitrile gradient in $25 \mathrm{~min}$ at a flow of $12 \mathrm{~mL}^{\mathrm{min}}{ }^{-1} . \mathrm{Rt}=13.2 \mathrm{~min}$. 9 was isolated as a white powder with a yield of $27 \%$ (8.60 $\mathrm{mg}$ ) and a HPLC purity of 95\%.

\section{K(Pyro)DKPPR, 12.}

After Fmoc deprotection, the reaction between FmocK(Pyro-a) (1.5 eq) and peptide D(OtBu)K(Boc)PPR(Pbf)Wang resin 10 was performed with HBTU (3 eq), NMP (3 eq) and NMM ( 9 eq) in DMF and the mixture was stirred for $12 \mathrm{~h}$ to conduct to the Fmoc and lateral protected compound 11. The final Fmoc protection was removed using piperidine. The resin was dried under vacuum and then cleaved (with full deprotection of lateral chains) using TFA/TIPS/water (92.5/2.5/5\%) for $2 \mathrm{~h}$. The acidic resin was filtered and washed with $\mathrm{CH}_{2} \mathrm{Cl}_{2}$ and EtOH. The filtrate was dried under vacuum and the compound was precipitated in ether by centrifugation. The final product was purified by preparative HPLC using acetonitrile/water $(0.1 \%$ TFA; $10 / 90)$ to $100 \%$ acetonitrile gradient in 15 $\mathrm{min}$, followed by isocratic acetonitrile for $10 \mathrm{~min}$ at a flow of $12 \mathrm{~mL} \cdot \mathrm{min}^{-1}$. Rt $=12.9 \mathrm{~min} .12$ was isolated as a dark green powder with a yield of $25 \%$ (15.57 mg) and a HPLC purity of $100 \%$.

\section{Alk-K(Pyro-a)DKPPR, 13.}

Following the synthesis of the product $\mathbf{1 1}$ on resin, the coupling reaction with (RS/SR)-6 (1.5 eq) was performed in presence of PyBOP ( 3 eq) and DIPEA (3 eq) in DMF, and the reaction mixture was stirred for $12 \mathrm{~h}$. The resin obtained was dried under vacuum and then cleaved (with full deprotection of lateral chains) using TFA/TIPS/water $(92.5 / 2.5 / 5 \%)$ for $2 \mathrm{~h}$ then filtered and washed with $\mathrm{CH}_{2} \mathrm{Cl}_{2}$ and $\mathrm{EtOH}$. The filtrate was dried under vacuum and the compound was precipitated in ether by centrifugation. The final product was purified using an Armen SPOT Prep system (high pressure, preparative liquid chromatography) using a column, using acetonitrile/water $(0.1 \%$ TFA; $10 / 90$ ) to $100 \%$ acetonitrile gradient in $15 \mathrm{~min}$, followed by isocratic acetonitrile for $10 \mathrm{~min}$ at a flow of 15 mL.min ${ }^{-1} . R \mathrm{t}=18.3 \mathrm{~min} .13$ was isolated as a dark green powder with a yield of $19 \%$ (8.25 mg) and a HPLC purity of $98 \%$.

\section{Photophysical properties}

The set ups and the methods have been already described in a previous study. ${ }^{25}$

\section{Photobleaching of Pyropheophorbide-a}

The studies of photobleaching were performed with a red laser $\left(\lambda=668 \mathrm{~nm}\right.$ and $\left.P=10 \mathrm{~mW} \cdot \mathrm{cm}^{-2}\right)$. The solutions of Pyro-a, 12 and 13 were prepared in order to have an absorbance around 0.2 to follow the evolution of fluorescence and singlet oxygen emission. The solutions were irradiated and the photophysical properties of each com- 
pound were evaluated at different times of irradiation: 0,5 , $10,15,20,25,30,35,40,45,50,55$ and $60 \mathrm{~min}$ with the same instruments as described below.

\section{Homolysis of Alk}

EPR spectra were recorded as previously described ${ }^{26}$ except the microwave power was at $4.5 \mathrm{~mW}$, modulation amplitude et $2 \mathrm{G}$, a sweep time of $30 \mathrm{~s}$ for a single scan and $25 \mu \mathrm{L}$ capillaries (Hirschmann) were used. 5(Diethoxyphosphoryl)-5-methyl-1-pyrroline-N-oxide (DEPMPO) was synthesized as reported in the literature. ${ }^{21}$ DEPMPO was stored in a stock solution at $0.5 \mathrm{M}$ in acetonitrile. The intensity of the EPR spectra was obtained by calculating the double integral of the EPR spectra. In case of multiple component spectra, spectra were simulated using Easyspin toolbox under Matlab (Mathworks) environment. ${ }^{27}$ The parameters used for simulation are presented in Supporting information table S2. The double integral of each component of the simulated spectra was used to get the intensity of each component. Initial rates were calculated by performing a linear fit on the 4 first points of the kinetics using OriginPro, version 8, fitting tool.

\section{Affinity tests}

Competitive binding to recombinant NRP-1 protein

The binding of compounds for NRP-1 protein was evaluated in terms of the half maximal inhibitory concentration ( $\mathrm{IC}_{50}$ values) through a competitive assay as previously described $^{28}$. (See SI)

\section{ASSOCIATED CONTENT}

Supporting Information. "This material is available free of charge via the Internet at http://pubs.acs.org." S1. Synthesis and analytical characterizations of $\mathbf{2},(R R / S S)-\mathbf{4},(R S / S R)-\mathbf{4}$, $(R S / S R)-5$ and $(R S / S R)-6,9,12$ and 13. S2. Photophysical properties. S3. Homolysis studies. S4. Competitive binding to recombinant NRP-1 protein.

\section{AUTHOR INFORMATION}

\section{Corresponding Author}

* celine.frochot@univ-lorraine.fr; Tel.: +33-3-72-74-37-80; g.audran@univ-amu.fr; Tel.: +33-4-91-28-88-62

\section{Author Contributions}

The manuscript was written through contributions of all authors. All authors have given approval to the final version of the manuscript.

\section{Funding Sources}

This research received no external funding.

\section{ACKNOWLEDGMENT}

We gratefully acknowledge François Courtier, Marc Basler and Dr. David Martel (Institut Charles Sadron, Strasbourg, France) for designing \& building of the illumination chamber. The authors thank the French Ministry of Research and the REseauNAtional de Rpeinter-Disciplinaire (RENARD, Fédération IR-RPE CNRS \#3443). Dr. Elena Gimenez-Arnau (Dermatochemistry Laboratory, University of Strasbourg, France) is acknowledged for providing us with DEPMPO. We also aknowledge André Merlin, LERMAB, CNRS, Université de Lorraine for his help with the RPE experiments, Olivier Fabre,
LCPM, CNRS, Université de Lorraine, for the NMR experiments and Serge Mordon, ONCOTHAI, INSERM, Université de Lille, $\mathrm{CHU}$ for the loan of the lighting equipment.

\section{ABBREVIATIONS}

Alk, alkoxyamine; AMD, age-related macular degeneration; DCM, dichloromethane; DIPEA, Diisopropylethylamine; DMF, diméthylformamide; DMP, Dess-Martin periodinane; DO, optical density; EDCI, $N$-Ethyl- $N$ '-(3dimethylaminopropyl)carbodiimide hydrochloride; EPR, Electronic paramagnetic resonance; HBTU, $N, N, N^{\prime}, N^{\prime}$ Tetramethyl-0-(1H-benzotriazol-1-yl)uronium hexafluorophosphate); HO*, hydroxyl radical; HPLC, high performance liquid chromatography; HR-MS, high-resolution mass spectrometry; NBS, $N$-bromosuccinimide; NHS, $N$ hydroxysuccinimide; NMM, $N$-methylmorpholine; NMP, Nitroxide Mediated Polymerization; NMR, nuclear magnetic resonance; NO, nitric oxide; NRP-1, neuropilin-1; $\mathrm{O}_{2}$, molecular oxygen; ${ }^{1} \mathrm{O}_{2}$, singlet oxygen; $\mathrm{O}_{2} \cdot{ }^{-}$, superoxide anion; PDT, photodynamic therapy; pip, piperidine; PS, photosensitizer; PTT, photothermal therapy; PyBOP, Benzotriazole-1-yl-oxytris-pyrrolidino-phosphonium hexafluorophosphate; Pyro-a, pyropheophorbide-a; ROS, reactive oxygen species; TFA, trifluoroacetic acid; THF, tetrahydrofuran; TIPS, triisopropylethylamine; TLC, thin layer chromatography; UV, ultra-violet; VEGF, vascular endothelial growth factor.

\section{REFERENCES}

(1) Hamblin, M. Advances in Photodynamic Therapy: Basic, Translational, and Clinical; Artech House, 2008.

(2) See, K. L.; Forbes, I. J.; Betts, W. H. Oxygen Dependency of Photocytotoxicity with Haematoporphyrin Derivative. Photochemistry and Photobiology 1984, 39 (5), 631-634. https://doi.org/10.1111/j.1751-1097.1984.tb03902.x.

(3) Larue; Myrzakhmetov; Ben-Mihoub; Moussaron; Thomas; Arnoux; Baros; Vanderesse; Acherar; Frochot. Fighting Hypoxia to Improve PDT. Pharmaceuticals 2019, 12 (4), 163. https://doi.org/10.3390/ph12040163.

Kovtun, G. A.; Aleksandrov, A. L.; Golubev, V. A. Interaction of Peroxide Radicals with Esters of Hydroxylamines. Russ Chem Bull 1974, 23 (10), 2115-2121. https://doi.org/10.1007/BF00921266.

Bertin, D.; Gigmes, D.; Marque, S. R. A.; Tordo, P. Kinetic Subtleties of Nitroxide Mediated Polymerization. Chem. Soc. Rev. 2011, 40 (5), 2189 https://doi.org/10.1039/c0cs00110d.

(6) Bagryanskaya, E. G.; Marque, S. R. A. Chapter 2:Kinetic Aspects of Nitroxide Mediated Polymerization. In Nitroxide Mediated Polymerization; 2015; pp 45-113. https://doi.org/10.1039/9781782622635-00045.

(7) Moncelet, D.; Voisin, P.; Koonjoo, N.; Bouchaud, V.; Massot, P.; Parzy, E.; Audran, G.; Franconi, J.-M.; Thiaudière, E.; Marque, S. R. A.; Brémond, P.; Mellet, P. Alkoxyamines: Toward a New Family of Theranostic Agents against Cancer. Molecular Pharmaceutics 2014, 11 (7), 2412-2419. https://doi.org/10.1021/mp5001394.

(8) Yamasaki, T.; Buric, D.; Chacon, C.; Audran, G.; Braguer, D.; Marque, S. R. A.; Carré, M.; Brémond, P. Chemical Modifications of Imidazole-Containing Alkoxyamines Increase C-ON Bond Homolysis Rate: Effects on Their Cytotoxic Properties in Glioblastoma Cells. Bioorganic \& Medicinal Chemistry 2019, 27 (10), 1942-1951. https://doi.org/10.1016/j.bmc.2019.03.029.

(9) Popova, N. A.; Sysoeva, G. M.; Nikolin, V. P.; Kaledin, V. I.; Tretyakov, E. V.; Edeeva, M. V.; Balakhnin, S. M.; Lushnikova, E. L.; Audran, G.; Mark, S. Comparative Study of Toxicity of Alkoxyamines In Vitro and In Vivo. Bulletin 
of Experimental Biology and Medicine 2017, 164 (1), 4953. https://doi.org/10.1007/s10517-017-3924-6.

(10) Benachour, H.; Frochot, C.; Vanderesse, R.; Guillemin, F.; Barberi-Heyob, M. Targeting Strategies in Photodynamic Therapy for Cancers Treatment. In Brain Cancer, Tumor Targeting and Cervical Cancer; Salvatti, E., Ed.; Novapublishers, 2011; pp 1-38.

(11) Krishnamurthy, S.; Witmer, P. Optimal Light Dose for Interstitial Photodynamic Therapy in Treatment for Malignant Brain Tumors. Lasers Surg. Med. 2000, 27, 224$234 . \quad$ https://doi.org/10.1002/10969101(2000)27:3<224::AID-LSM4>3.0.CO;2-\%23.

(12) Tirand, L.; Frochot, C.; Vanderesse, R.; Thomas, N.; Trinquet, E.; Pinel, S.; Viriot, M.-L.; Guillemin, F.; BarberiHeyob, M. A Peptide Competing with VEGF165 Binding on Neuropilin-1 Mediates Targeting of a Chlorin-Type Photosensitizer and Potentiates Its Photodynamic Activity in Human Endothelial Cells. Journal of Controlled Release 2006, 111 (1-2), 153-164. https://doi.org/10.1016/j.jconrel.2005.11.017.

(13) Corbin, T. F.; Hahn, R. C.; Shechter, H. Cyclopropylbenzene. Organic Syntheses 2003, 30-30. https://doi.org/10.1002/0471264180.os044.10.

(14) Audran, G.; Bikanga, R.; Brémond, P.; Edeleva, M.; Joly, J.P.; Marque, S. R. A.; Nkolo, P.; Roubaud, V. How Intramolecular Hydrogen Bonding (IHB) Controls the CON Bond Homolysis in Alkoxyamines. Org. Biomol. Chem. 2017, 15 (39), 8425-8439. https://doi.org/10.1039/C70B02223A.

(15) Home - The Cambridge Crystallographic Data Centre (CCDC) https://www.ccdc.cam.ac.uk/ (accessed Oct 1, 2019).

(16) Dess, D. B.; Martin, J. C. A Useful 12-I-5 Triacetoxyperiodinane (the Dess-Martin Periodinane) for the Selective Oxidation of Primary or Secondary Alcohols and a Variety of Related 12-I-5 Species. J. Am. Chem. Soc. 1991, $113 \quad$ (19), 7277-7287. https://doi.org/10.1021/ja00019a027.

(17) Bal, B. S.; Childers, W. E.; Pinnick, H. W. Oxidation of $\alpha, \beta-$ Un Saturated Aldehydes. Tetrahedron 1981, 37 (11), 2091-2096. https://doi.org/10.1016/S00404020(01)97963-3.

(18) Youssef, Z.; Yesmurzayeva, N.; Larue, L.; Jouan-Hureaux, V.; Colombeau, L.; Arnoux, P.; Acherar, S.; Vanderesse, R.; Frochot, C. New Targeted Gold Nanorods for the Treatment of Glioblastoma by Photodynamic Therapy. Journal of Clinical Medicine 2019, 8 (12), 2205. https://doi.org/10.3390/jcm8122205.

(19) Bertrand, P. Hyperfine Structure of a Spectrum in the Isotropic Regime. In Electron Paramagnetic Resonance Spectroscopy: Fundamentals; Bertrand, P., Ed.; Springer
International Publishing: Cham, 2020; pp 31-59. https://doi.org/10.1007/978-3-030-39663-3_2.

(20) Pryor, W. A. Bio-Assays for Oxidative Stress Status; Elsevier, 2012.

(21) Barbati, S.; Clément, J. L.; Olive, G.; Roubaud, V.; Tuccio, B.; Tordo, P. 31P Labeled Cyclic Nitrones: A New Class of Spin Traps for Free Radicals in Biological Milieu. In Free Radicals in Biology and Environment.; Nato Science Partnership Subseries: 3; Springer Netherlands, 1997; pp 3947.

(22) Lauricella, R.; Tuccio, B. Detection and Characterisation of Free Radicals After Spin Trapping. In Electron Paramagnetic Resonance Spectroscopy: Applications; Bertrand, P., Ed.; Springer International Publishing: Cham, 2020; pp 51-82. https://doi.org/10.1007/978-3-030-39668-8_3.

(23) Cauble, D. F.; Lynch, V.; Krische, M. J. Studies on the Enantioselective Catalysis of Photochemically Promoted Transformations: "Sensitizing Receptors" as Chiral Catalysts. J. Org. Chem. 2003, 68 (1), 15-21. https://doi.org/10.1021/jo020630e.

(24) Audran, G.; Brémond, P.; Marque, S. R. A.; Yamasaki, T. CON Bond Homolysis of Alkoxyamines, Part 11: Activation of the Nitroxyl Fragment. J. Org. Chem. 2016, 81 (5), 1981-1988. https://doi.org/10.1021/acs.joc.5b02790.

(25) Stallivieri, A.; Colombeau, L.; Jetpisbayeva, G.; Moussaron, A.; Myrzakhmetov, B.; Arnoux, P.; Acherar, S.; Vanderesse, R.; Frochot, C. Folic Acid Conjugates with Photosensitizers for Cancer Targeting in Photodynamic Therapy: Synthesis and Photophysical Properties. Bioorganic \& Medicinal Chemistry 2017, 25 (1), 1-10. https://doi.org/10.1016/j.bmc.2016.10.004.

(26) Twardoch, M.; Messai, Y.; Vileno, B.; Hoarau, Y.; Mekki, D. E.; Felix, O.; Turek, P.; Weiss, J.; Decher, G.; Martel, D. Development of an Electron Paramagnetic Resonance Methodology for Studying the Photo-Generation of Reactive Species in Semiconductor Nano-Particle Assembled Films. Molecular Physics 2018, 116 (12), 1558-1564. https://doi.org/10.1080/00268976.2018.1433882.

(27) Stoll, S.; Schweiger, A. EasySpin, a Comprehensive Software Package for Spectral Simulation and Analysis in EPR. Journal of Magnetic Resonance 2006, 178 (1), 42-55. https://doi.org/10.1016/j.jmr.2005.08.013.

(28) Thomas, N.; Pernot, M.; Vanderesse, R.; Becuwe, P.; Kamarulzaman, E.; Da Silva, D.; François, A.; Frochot, C.; Guillemin, F.; Barberi-Heyob, M. Photodynamic Therapy Targeting Neuropilin-1: Interest of Pseudopeptides with Improved Stability Properties. Biochemical Pharmacology 2010, $80 \quad$ (2), 226-235 https://doi.org/10.1016/j.bcp.2010.03.036. 


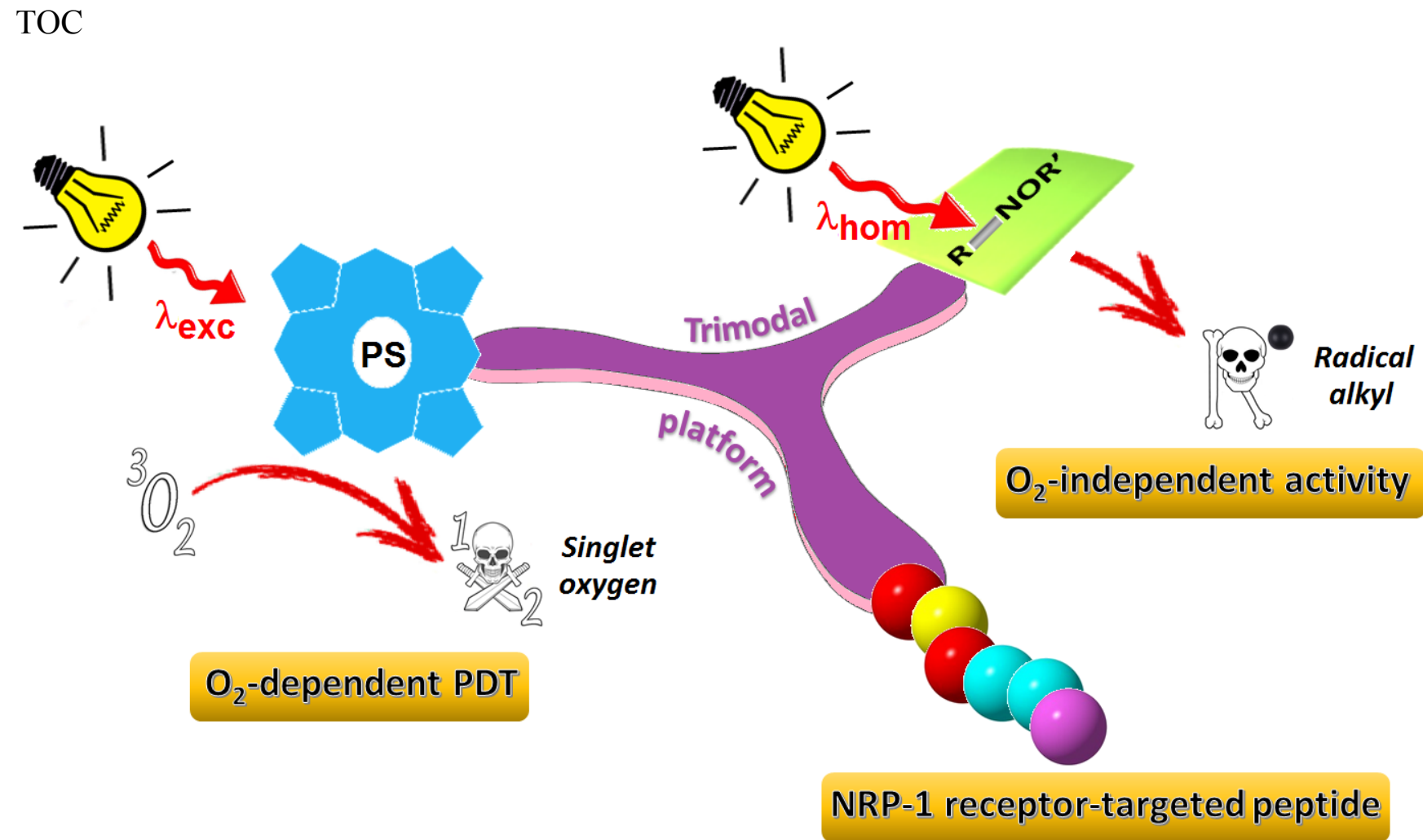

